\title{
Some aspects of glass-ceramic superconductors
}

\begin{abstract}
B K CHAUDHURI
Solid State Physics Department, Indian Association for the Cultivation of Science, Calcutta 700032 , India

Abstract. In this review article we have discussed, in brief, the general procedure for making glass-ceramic superconductors and some of their physical properties. All these glasses which become superconductors after properly annealing at higher temperatures are, in general, transition metal oxides (TMO) with copper ions. So the usual theoretical models of polaronic hopping conduction mechanisms are valid for explaining the semiconducting behaviour of these oxide glasses. Some of the transport properties of the glass-ceramie (GC) phases, viscosity of the glassy state, wire making feasibility etc have also been discussed in short.
\end{abstract}

Keywords. Glass-ceramics; superconductors.

\section{Introduction}

The semiconducting transition metal oxide (TMO) glasses, in general, have been vastly studied during the last couple of decades (Mott and Davis 1979). This is because of their probable technological applications (Hirashima et al 1987; Sakuri and Yamaki 1985; Nakamura and Ichinose 1987). Above all, these glasses with various compositions are relatively easy to prepare compared to other non-oxide glasses. Moreover, the cost of sample preparation is also low and for these reasons a small research group having moderate research facilities can start working on different aspects of TMO glasses. But the investigations of the structural as well as the physical properties of such glassy systems provide wealth of new informations about the basic mechanism of semiconducting behaviour in these and similar other glasses. Magnetic, optical, dielectric, and thermal properties are also equally important for all these glasses elucidating many interesting features (Mott and Davis 1979).

However, it had not been guessed earlier (before 1987) that some of the TMO glasses might even show high temperature superconducting behaviour in their crystalline (called glass-ceramic or GC) phases obtained by annealing the glass samples at higher temperatures (below the respective melting points).

After the discovery of high $T_{\mathrm{c}}$ superconductors in the $\mathrm{Y}-(\mathrm{Ba}, \mathrm{Sr})-\mathrm{Cu}-\mathrm{O}$ (Bednorz and Muller 1986), $\mathrm{Bi}-\mathrm{Sr}-\mathrm{Ca}-\mathrm{Cu}-\mathrm{O}$ (Michel et al 1987; Maeda et al 1988) etc systems (where $\mathrm{Cu}$ is the transition metal atom), special importance has also been attributed to make these high $T_{\mathrm{c}}$ materials from the corresponding glassy phases. It was first shown by Komatsu et al (1987) that the glass made by melting $\mathrm{Y}-\mathrm{Ba}-\mathrm{Cu}-\mathrm{O}$ oxide becomes superconductor in the corresponding GC phase. This is definitely an important discovery. This is because, the superconductors obtained by this GC route would be highly homogeneous, their grain sizes could be controlled, wires/tapes could be drawn from the glasses which could then be converted in the corresponding high $T_{\mathrm{c}}$ phases and necessary technology could be developed for the proper utilization of these wires/tapes. Mixing of the components occur at molecular level in the melts. Almost fully dense, uniform, pore-free materials can be fabricated from the glassy phase leading to high critical density of the prepared superconductors. Heat treatments of 
the quenched glasses can lead to the metastable crystalline phases having unusual properties which cannot be synthesized by the usual normal means. However, there are also certain limitations of the melt quenching approach. The components should not be volatile at about one to two hundred degrees above the melting temperature. The melt must not phase separate and not react with the container used for the melt. Recently, containerless melting technique is being used to make pure glassy phases.

Another part of research with these precursor glasses is to understand their physical properties and to know why these glasses become superconductors in their glass-ceramic phases while many similat TMO glasses do not show superconductivity in their respective GC phases. Therefore, proper understanding of the behaviour of these glasses is also necessary. However, this second part of research is in the rudimentary stage and we will not discuss this part in the present article.

\section{Preparation of the glassy phase}

The starting materials (carbonates and metal oxides), in general, are well mixed in appropriate proportions and then melted in $\mathrm{Pt}$ or crystalline $\mathrm{Al}_{2} \mathrm{O}_{3}$ crucibles between 1000 and $1300^{\circ} \mathrm{C}$ for a few hours. Before melting, pre-heating around $500^{\circ} \mathrm{C}$ is essential.

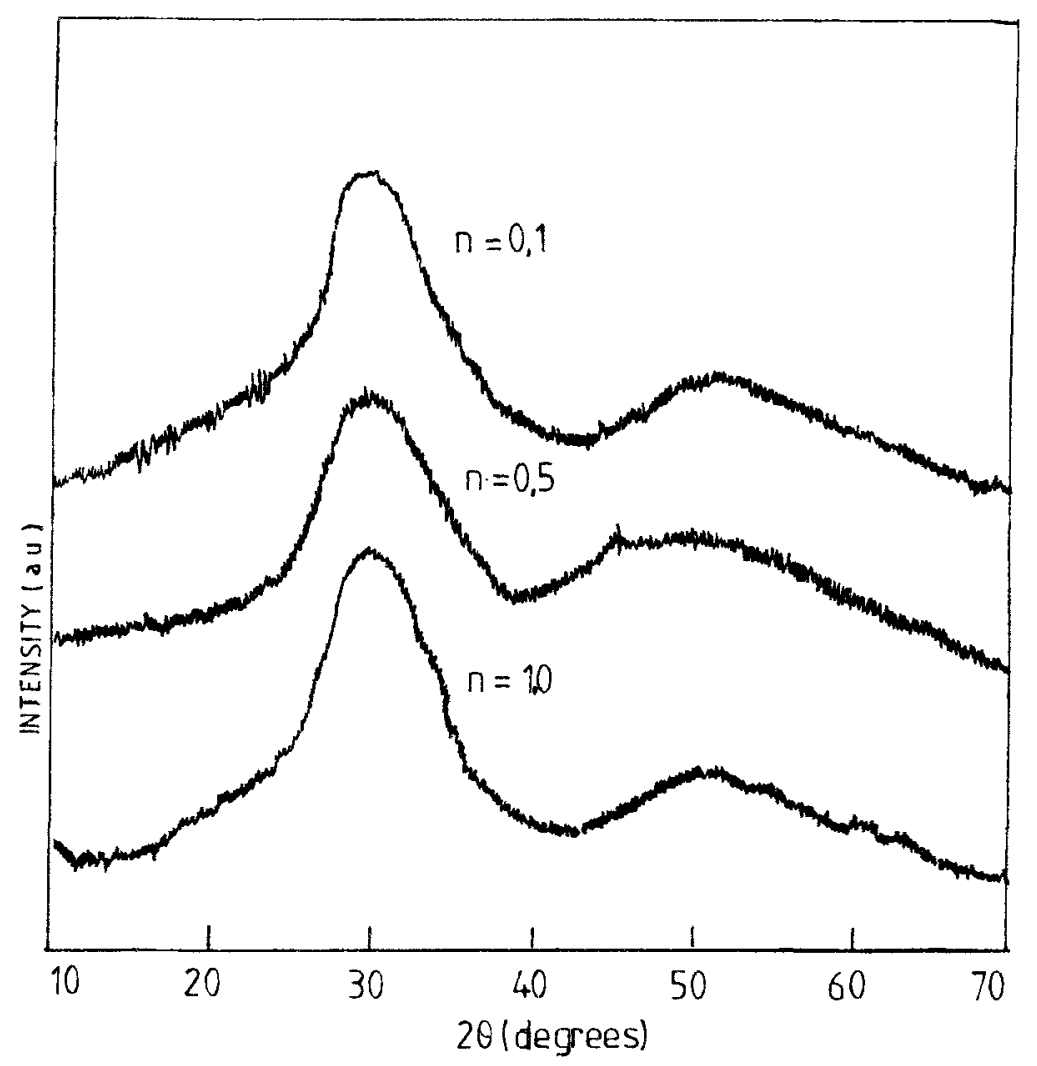

Figure 1. X-ray diffraction pattern of a typical $\mathrm{Pb}$-doped $\mathrm{Bi}_{4-n} \mathrm{~Pb}_{n} \mathrm{Sr}_{3} \mathrm{Ca}_{3} \mathrm{Cu}_{4} \mathrm{O}_{x}(n=0 \cdot 1$, 0.5 and 1.0 ) glass. 
The melt is rapidly quenched by a twin roller or by pressing between two metal plates resulting in black opaque glass with metallic lustre. Now a days, containerless glass making process has also been well developed to avoid contamination effect. $\mathrm{X}$-ray diffraction patterns of some typical glasses, viz. $\mathrm{Bi}_{4-x} \mathrm{~Pb}_{x} \mathrm{Sr}_{3} \mathrm{Ca}_{3} \mathrm{Cu}_{y} \mathrm{O}_{x}(x=0 \cdot 1$, $0 \cdot 5,1 \cdot 0$ ), are shown in figure 1 indicating an amorphous character with broad peaks. Sometimes low intensity diffraction due to some unreacted $\mathrm{CaO}$ etc might appear in the diffraction pattern. Furthermore, phase separation is also observed in such glasses (Chaudhuri and Som 1992; Mollah et al 1994). The appearance of crystalline superconducting phases with increase of annealing time is shown in figure 2 . The following procedure is generally followed to make good quality glassy precursors for high $T_{\mathrm{c}}$ superconductors: (i) Mixing of the raw oxide (if carbonates are used they should be calcined around $900^{\circ} \mathrm{C}$ for $8-10 \mathrm{~h}$ to decompose carbonates) materials for an hour or more with pure acetone or alcohol, (ii) the mixture is pre-heated at $500^{\circ} \mathrm{C}$ for about $5 \mathrm{~h}$, (iii) the preheated oxide is melted between 1000 and $1300^{\circ} \mathrm{C}$ for 1 to $2 \mathrm{~h}$, (iv) the melt is quenched rapidly between two copper blocks to obtain the glassy precursors for high $T_{\mathrm{c}}$ superconductors and $(\mathrm{v})$ the glasses thus obtained are properly heat-treated under appropriate conditions to get high $T_{\mathrm{c}}$ superconducting oxides.

We are discussing below some of the most common glasses and the corresponding superconducting glass-ceramics.

\section{3. $\mathrm{Bi}-\mathrm{Sr}-\mathrm{Ca}-\mathrm{Cu}-\mathrm{O}$ system}

Bi-based glasses have been widely used for the preparation of high $T_{\mathrm{c}}$ superconducting materials. Several glasses with different concentrations of $\mathrm{Bi}$ or the transition metal

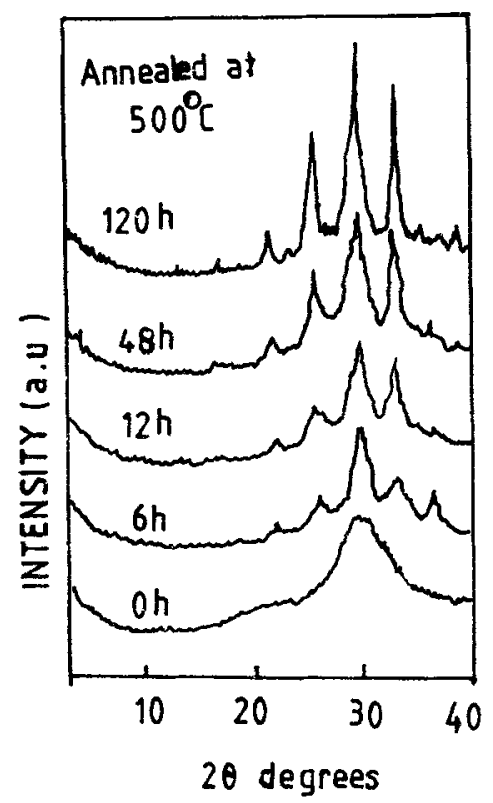

Figure 2. Change of $\mathrm{X}$-ray diffraction patterns depending on annealing time for a typical $\mathrm{Bi}_{2} \mathrm{Sr}_{2} \mathrm{Ca}_{1} \mathrm{Cu}_{2} \mathrm{O}_{x}$ glass. 
ions have been prepared (Tohge et al 1989) and their superconducting properties studied. The glass forming region of a typical $\mathrm{Bi}-\mathrm{Sr}-\mathrm{Ca}-\mathrm{Cu}-\mathrm{O}$ system is shown in the phase diagram in figures $3 \mathrm{a}, \mathrm{b}$. Many other glass compositions of this group follow similar phase diagram. A wide glass forming region as shown by the broken line in figure 3 exists in this system. It is highly interesting to note that no glass former oxide is present in this system and the glass transition temperature $\left(T_{\mathrm{g}}\right)$ depends mainly on the $\mathrm{Bi}_{2} \mathrm{O}_{3}$ concentration in the glass as shown in figure 4 for a typical $\mathrm{Bi}_{x} \mathrm{SrCaCu}_{2} \mathrm{O}_{x}$. The DSC scan of a $\mathrm{Bi}-\mathrm{Sr}-\mathrm{Ca}-\mathrm{Cu}-\mathrm{O}$ glass showing $\mathrm{T}_{\mathrm{g}}$ and crystallization temperature $T_{\mathrm{x}}$, is drawn in figure 5 (Komatsu et al 1988). Influence of calcium content on $T_{\mathrm{x}}$ and $T_{\mathrm{g}}$ for some Bi-based glass is shown in figure 6. Zheng et al (1989) reported that the values of $T_{\mathrm{g}}$ and $T_{\mathrm{x}}$ decrease with increase in $\mathrm{CuO}$ or $\mathrm{Bi}_{2} \mathrm{O}_{3}$ concentration and increase with increasing the alkaline earth $(\mathrm{CaO}$ and $\mathrm{SrO})$
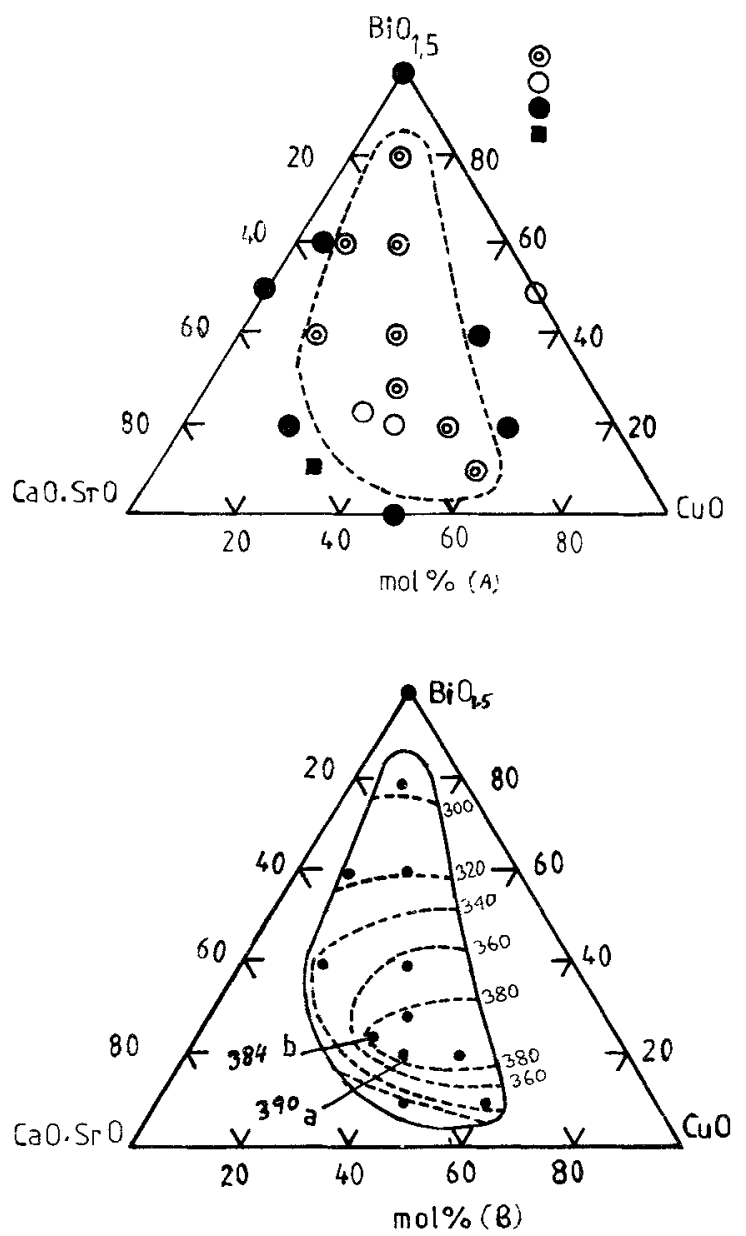

Figure 3. A. Phase diagram of a typical $\mathrm{BiO}_{1 \cdot 5}(\mathrm{SrO} \cdot \mathrm{CaO})_{0.5} \mathrm{CuO}, \mathrm{SrO} / \mathrm{CaO}=1$ composition. (a) $\mathrm{BiSrCaCu}{ }_{2} \mathrm{O}$ and (b) $\mathrm{Bi}_{2} \mathrm{Sr}_{2} \mathrm{Ca}_{2} \mathrm{Cu}_{3} \mathrm{O}_{y}$ (Tohge et al 1989). B. Isotherms of $T_{\mathrm{g}}$ in $\mathrm{Bi}_{1 \cdot 5}(\mathrm{SrO}$, $\mathrm{CaO})_{0.5} \mathrm{CuO}, \mathrm{SrO} / \mathrm{CaO}=1$. (a) $\mathrm{BiSrCaCu}_{2} \mathrm{O}_{y}$ and (b) $\mathrm{Bi}_{2} \mathrm{Sr}_{2} \mathrm{Ca}_{2} \mathrm{Cu}_{30}$ (Tohge et al 1989). (อ. Glass, $\mathrm{O}$, glass $+\mathrm{CaO}$;, crystal and $\mathbf{E}$, decomposition). 


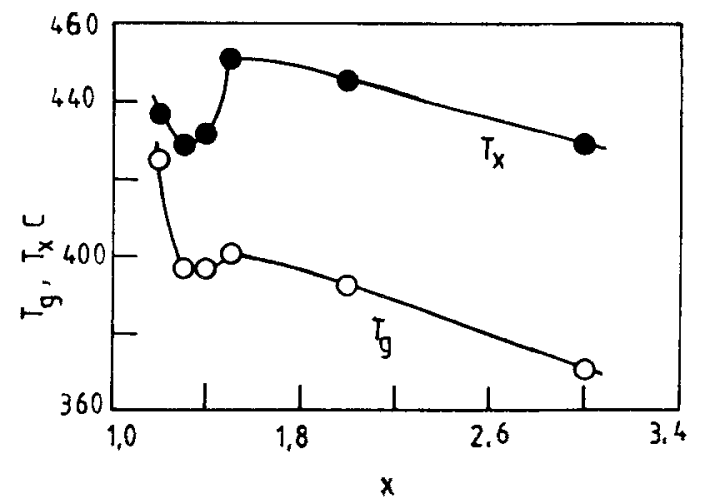

Figure 4. Effect of $\mathrm{Bi}$ content on $T_{\mathrm{z}}$ and $\mathrm{T}_{\mathrm{x}}$ for the $\mathrm{Bi}_{x} \mathrm{SrCaCu}_{2} \mathrm{O}_{y}$ glassy precursor (Bansal and Guire 1989).

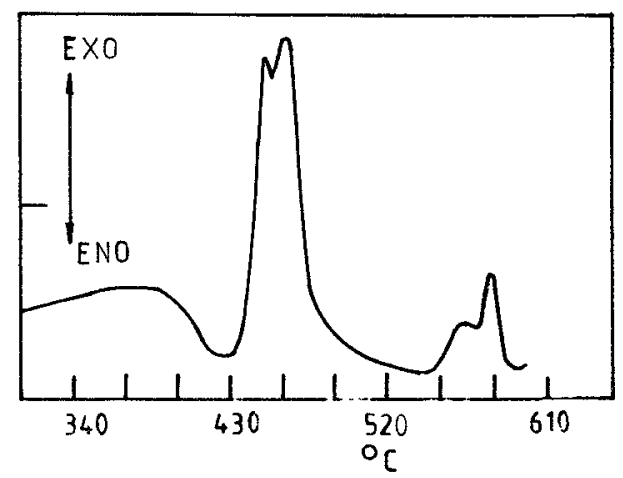

Figure 5. DSC scan of $\mathrm{Bi}_{1.5} \mathrm{SrCaCu}_{2} \mathrm{O}_{y}$ glass in inert atmosphere at a heating rate of $10^{\circ} \mathrm{C} / \mathrm{min}$ (Komatsu et al 1989).

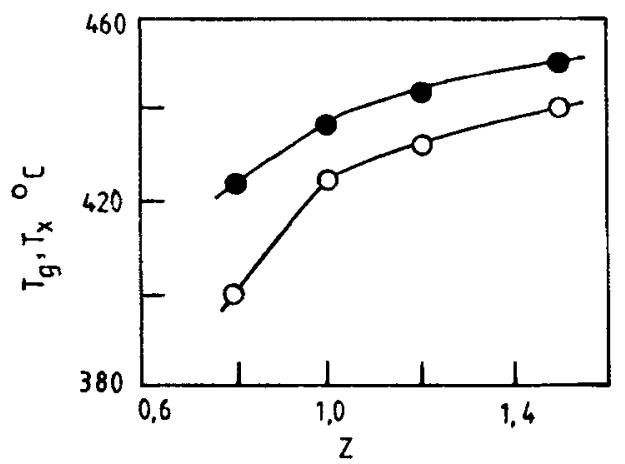

Figure 6. Influence of calcium content on $T_{x}$ and $T_{g}$ for the $\mathrm{Bi}_{1 \cdot 2} \mathrm{SrCa}_{z} \mathrm{Cu}_{2} \mathrm{O}_{y}$ glasses (Komatsu et al 1989). 
content. The difference $T_{\mathrm{x}}-T_{\mathrm{g}}$ called thermal stability factor is large for glasses with large $\mathrm{Bi}_{2} \mathrm{O}_{3}$ content. Therefore, $\mathrm{Bi}_{2} \mathrm{O}_{3}$ plays an important role in glass formation and also in thermal stability which is required for making glass fibre or glass tape.

\section{4. $\mathrm{Bi}-\mathrm{Pb}-\mathrm{Sr}-\mathrm{Ca}-\mathrm{Cu}-\mathrm{O}$ system}

This is another very important glassy precursor for high $T_{\mathrm{c}}$ superconductors with superconducting transition temperature $T_{\mathrm{c}}$ more than $115 \mathrm{~K}$ with $T_{\mathrm{c} 0}=100$ to $110 \mathrm{~K}$. The values of $T_{\mathrm{g}}$ and $T_{\mathrm{x}}$ (figure 7 for a typical $\mathrm{Pb}$ doped glass) increase slowly with increase of $\mathrm{Bi}_{2} \mathrm{O}_{3}$ content and reach a maximum for $x=3 \cdot 0$ (figure 8 ) and decrease with further increase of bismuth content.

\section{5. $\mathrm{Bi}-\mathrm{Sr}-\mathrm{Ca}-\mathrm{Li}-\mathrm{Cu}-\mathrm{O}$ system}

This is another glassy system almost similar in its behaviour with that of the $\mathrm{Bi}-\mathrm{Pb}-$ $\mathrm{Sr}-\mathrm{Ca}-\mathrm{Cu}-\mathrm{O}$ type system discussed above. The main functions of $\mathrm{Li}$ doping are to decrease the glass melting temperature as well as glass annealing temperature required for making them superconductors. The superconducting transition temperature is also increased in such systems by about $5-10 \mathrm{~K}$.

\section{6. $\mathrm{Y}-\mathrm{Ba}-\mathrm{Cu}-\mathrm{O}$ system}

It is very difficult to make glass with these oxides $\left(\mathrm{Y}_{2} \mathrm{O}_{3}, \mathrm{BaCO}_{3}\right.$ and $\left.\mathrm{CuO}\right)$ requiring high melting temperature $\left(1300-1400^{\circ} \mathrm{C}\right)$ and high quenching rate. However, with little $\mathrm{B}_{2} \mathrm{O}_{3}(1-5 \mathrm{wt} \%)$ good quality glass of such system can be prepared. In such a case, however, the superconducting transition temperature is reduced below $80 \mathrm{~K}$ or so. However, there is some report that rapid quenching of small droplets of $\mathrm{YBa}_{2} \mathrm{Cu}_{3} \mathrm{O}_{x}$ melt on steel plates resulted (Koo et al 1889) in an amorphous material which showed $T_{\mathrm{g}}=330^{\circ} \mathrm{C}$ and $T_{\mathrm{x}}=780^{\circ} \mathrm{C}$.

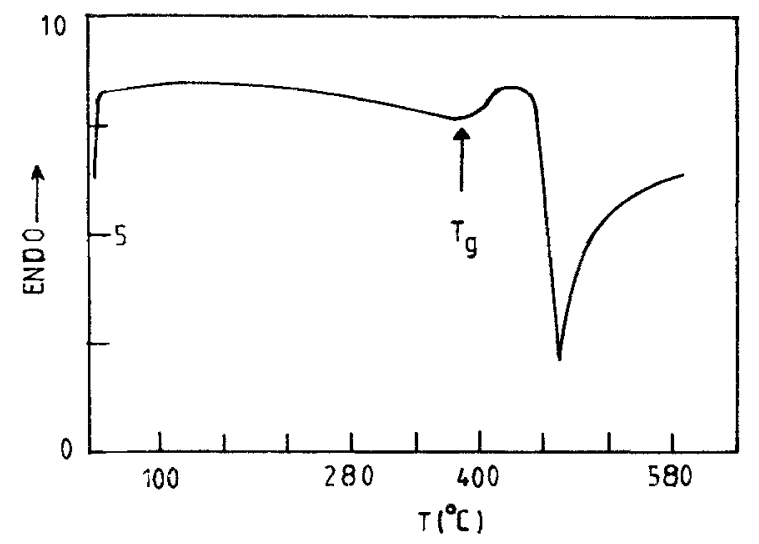

Figure 7. DSC scan of $\mathrm{Bi}_{1 \cdot 5} \mathrm{~Pb}_{0.5} \mathrm{Sr}_{2} \mathrm{Ca}_{2} \mathrm{Cu}_{3} \mathrm{O}_{y}$ glass recorded at a heating rate of $40^{\circ} / \mathrm{min}$ in argon (Bansal 1990). 


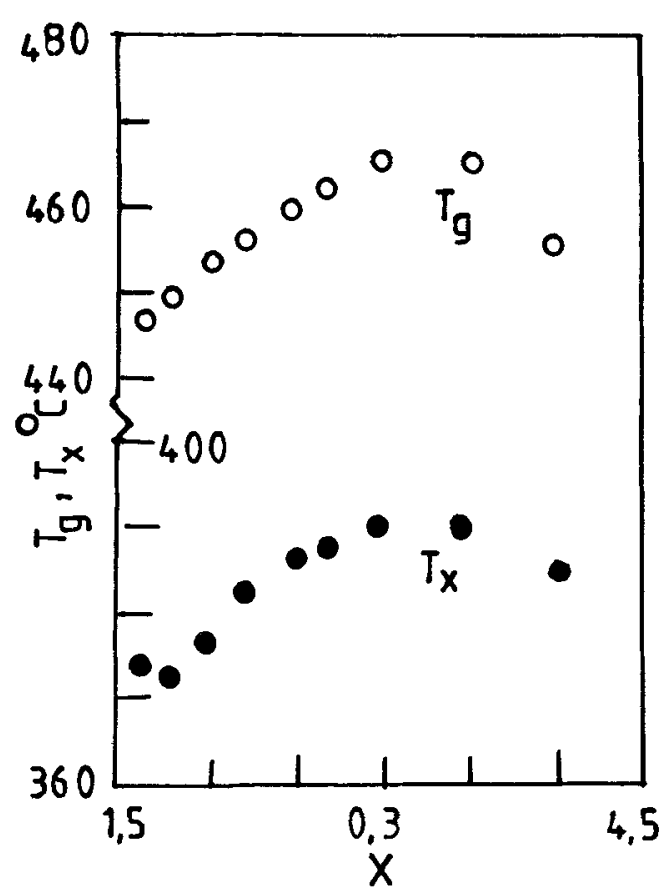

Figure 8. Dependence of $T_{\mathrm{g}}$ and $T_{\mathrm{x}}$ of $\mathrm{Bi}_{x} \mathrm{~Pb}_{0 \cdot 4} \mathrm{Sr}_{2} \mathrm{Ca}_{2} \mathrm{Cu}_{3} \mathrm{O}_{y}$ glasses on their bismuth content (Komatsu et al 1990).

\section{7. $\mathbf{T l}-\mathrm{Ba}-\mathrm{Ca}-\mathrm{Cu}-\mathrm{O}$ system}

Report on the preparation of $\mathrm{Tl}_{2} \mathrm{Ba}_{2} \mathrm{CaCu}_{2} \mathrm{O}$ and $\mathrm{Tl}_{2} \mathrm{Ba}_{2} \mathrm{Ca}_{2} \mathrm{Cu}_{3} \mathrm{O}_{x}$ glasses (Nassau et al 1989) is available in the literature. But loss of $\mathrm{Tl}_{2} \mathrm{O}_{3}$ during melting makes it difficult to get superconducting glass-ceramic phases.

\section{Ba-K( $\mathrm{Li}, \mathrm{Na})-\mathrm{Bi}-\mathrm{O}$ type non copper oxide system}

This is a new glass system showing very interesting semiconductor-metal-semiconductor like transition even in the glassy phase (Bera et al 1994; Mollah et al 1994).

\section{9. $\mathbf{B a}-\mathbf{P b}-\mathrm{Bi}-\mathrm{O}-\mathrm{type}$ non-copper oxide system}

This is also a new and very interesting glassy precursor for high $T_{\mathrm{c}}$ superconductors. These glasses can be prepared with different concentrations of $\mathrm{Pb}$ showing non-linear physical properties (Sadhukhan et al 1994). Recently, many other glasses like $\mathrm{V}-\mathrm{Bi}-$ $\mathrm{St}-\mathrm{Ti}-\mathrm{O}, \mathrm{V}-\mathrm{Bi}-\mathrm{Ba}-\mathrm{Ti}-\mathrm{O}, \mathrm{V}-\mathrm{Bi}-\mathrm{Cr}-\mathrm{Sr}-\mathrm{Ca}-\mathrm{O}$ etc have also been discovered showing some superconducting behaviour (around $20 \mathrm{~K}$ or below) in their glassy phases. However, elaborate investigations of such glasses have not yet been made. It is apparent that in the near future more and more glassy precursors for high $T_{\mathrm{c}}$ 
superconductors with many interesting physical and structural properties would be discovered. But the main problems related to the understanding of the mechanism of such superconducting transitions in these oxide glasses and the peculiar behaviour exhibited by some of these glassy precursors for high $T_{\mathrm{c}}$ superconductors like metal-insulator behaviour (Bera et al 1994), increase of ac conductivity and its superlinear behaviour in the low temperature region (Mollah et al 1994) etc are still not clear.

\section{Glass viscosity}

Temperature dependence of glass viscosity is very important for a successful drawing of the glass fibres. Generally, beam-bending technique has been used for the determination of viscosity in the glass transition range of the glasses like $\mathrm{Bi}_{x} \mathrm{SrCaCu}_{2} \mathrm{O}_{y}$ $(x=1.5$ to 2.7$)$ (Tatsumisago et al 1990). The temperature dependence of viscosity follows an Arrhenius behaviour with an activation energy, $E_{0}$ of 800 to $9980 \mathrm{~kJ} / \mathrm{mol}$. Glasses with lower $\mathrm{Bi}$ content showed lower $E_{0}$. Such a large value of $E_{0}$ indicates that from the $\mathrm{Bi}-\mathrm{Sr}-\mathrm{Ca}-\mathrm{Cu}-\mathrm{O}$ system glass fibres can be drawn only at around the glass softening point rather than from the pure melt because of high fluidity like water. Since the range $T_{\mathrm{x}}-T_{\mathrm{g}}$ is very narrow for these glasses, crystallization would be the main problem for drawing fibres at around the glass softening point. However, an increase in the $\mathrm{Bi}$ content in the glass lowers the value of $E_{0}$ and hence facilitate drawing glass fibres. Unfortunately, addition of $\mathrm{Bi}$ to a large extent lowers the value of $T_{\mathrm{c}}$. So an appropriate choice of the composition of glasses is necessary for the successful drawing of the glass fibres and then making them superconducting by properly annealing at a higher temperature. Temperature dependence of viscosity in a very narrow temperature range is shown in figure 9 where the shaded region shows the allowable fibre drawing range. The temperature dependence of viscosity of $\mathrm{Bi}_{4} \mathrm{Sr}_{3} \mathrm{Ca}_{3} \mathrm{Cu}_{4} \mathrm{O}_{y}$ glass is shown in figure 10 . The temperature dependence of the melt viscosity has been measured for the $\mathrm{Bi}_{2} \mathrm{Sr}_{2} \mathrm{Ca}_{1} \mathrm{Cu}_{2} \mathrm{O}_{y}$ glass. The melt viscosity

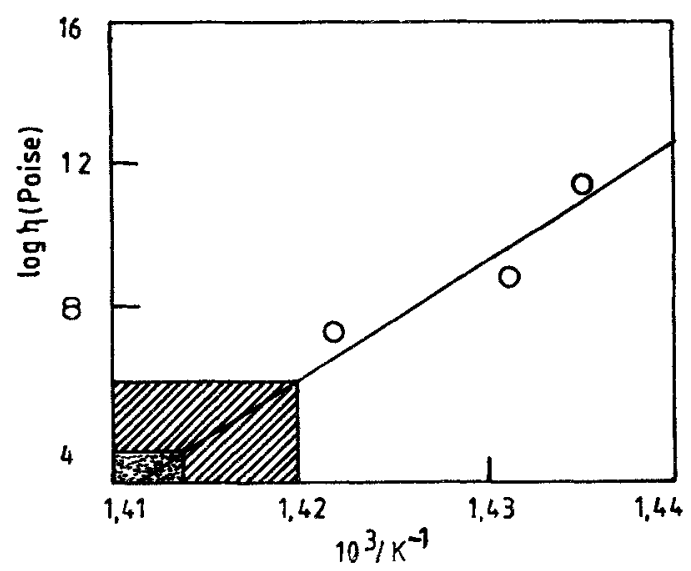

Figure 9. Temperature dependence of viscosity of the melt quenched $\mathrm{Bi}_{1.5} \mathrm{SrCaCu}_{2} \mathrm{O}_{y}$ glass. The allowable drawing range is shown as in the shade region (Onishi et al 1989). 


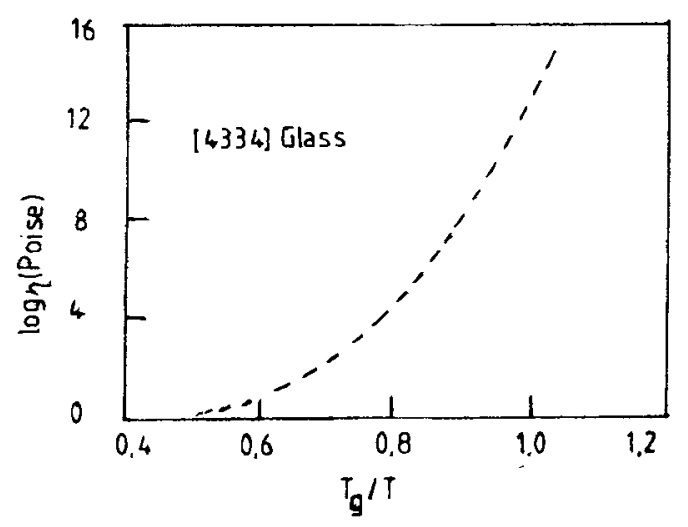

Figure 10. Temperature dependence of viscosity for the melt and glass of $\mathrm{Bi}_{4} \mathrm{Sr}_{3} \mathrm{Ca}_{3} \mathrm{Cu}_{4} \mathrm{O}_{y}$ composition (Zheng et al 1991a, b).

varies from 45 to 100 Poise in the temperature range of 885 to $985^{\circ} \mathrm{C}$ (LeBeau et al 1989).

\section{Crystallization process from glassy phase}

Crystallization process or crystallization kinetics is important for a successful drawing of the glass fibres. Non-isothermal (Tatsumisago et al 1989a, b; Tohge et al 1989; Bansal 1990) or isothermal (Zheng and Mackenzie 1991) differential scanning has been used to study the kinetics of crystallization in the Bi-based oxide glasses leading to superconductivity in their ceramic phases. The isothermal crystallization of a glass can be expressed by the Avrami equation (Avrami 1939) viz.

$$
x=1-\exp \left[-(k T)^{n}\right]
$$

where $x$ is the volume fraction crystallized after time $t, n$ the Avrami parameter which depends on the crystal growth morphology, and $k$ the crystallization rate constant which can be expressed as the activation energy, $R$ the gas constant and $T$ the isothermal absolute temperature. The values of $E_{\mathrm{a}}$ for crystallization of glasses of various compositions are found to vary from 290 to $489 \mathrm{~kJ} / \mathrm{mol}$. The value of the Avrami exponent for crystallization of the $\mathrm{Bi}_{4} \mathrm{Ca}_{3} \mathrm{Sr}_{3} \mathrm{Cu}_{4} \mathrm{O}_{y}$ glass was found (Zheng and Mackenzie 1991) to be close to 3 suggesting a three dimensional crystal growth at a constant number of nucleation state.

\section{Crystal phases obtained under heat treatment of glasses}

Time, temperature and atmosphere have great influence on the crystal formation from the glass phase under heat treatment studied by several researchers. Some results on the Bi-based glasses are discussed below. When a glass sample is heat-treated, it takes quite a long time to become crystalline, and this crystallization is not a continuous process leading to the final single superconducting phase. Several factors are involved 
to control the different phase formations. Composition, phase separation in the glass phase, annealing time, temperature, heating rate, cooling rate etc are important parameters to get a single superconducting crystalline phase from a typical glass phase under investigation.

Several authors (Tohge et al 1989; Tatsumisago et al 1990) have studied time $(T)$-temperature $(T)$-transformation $(T)$ diagram of the $\mathrm{Bi}-\mathrm{Sr}-\mathrm{Ca}-\mathrm{Cu}-\mathrm{O}$ system. $\mathrm{A}$ typical $T-T-T$ diagram for the $\mathrm{BiSrCaCu}_{2} \mathrm{O}_{y}$ glass is shown in figure 11. Each symbol is a mixture of crystalline phase. Figure 12 shows the $T-T-T$ diagrams for the $\mathrm{Bi}_{2} \mathrm{Sr}_{2} \mathrm{Ca}_{2} \mathrm{Cu}_{3} \mathrm{O}_{y}$ glass composition. The transformation behaviour of the melt cast material of $\mathrm{Bi}_{2} \mathrm{Sr}_{2} \mathrm{CaCu}_{2} \mathrm{O}_{x}$ composition into the 2212 superconducting phase is different in air and nitrogen atmospheres. Due to a large fraction of copper ions present as $\mathrm{Cu}(\mathrm{I})$ in these glasses, the crystallization mechanism is affected by the

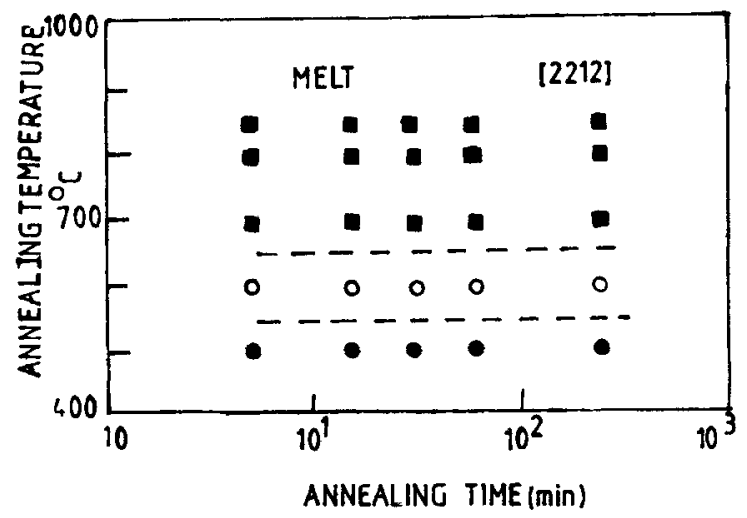

Figure 11. $T-T-T$ diagram for $\mathrm{BiSrCaCu}_{2} \mathrm{O}_{y}$ glass $(O$, glass; $O, 10 \mathrm{~K}$ phase; $\boldsymbol{W}, 80 \mathrm{~K}$ phase). (Tohge et al 1989).

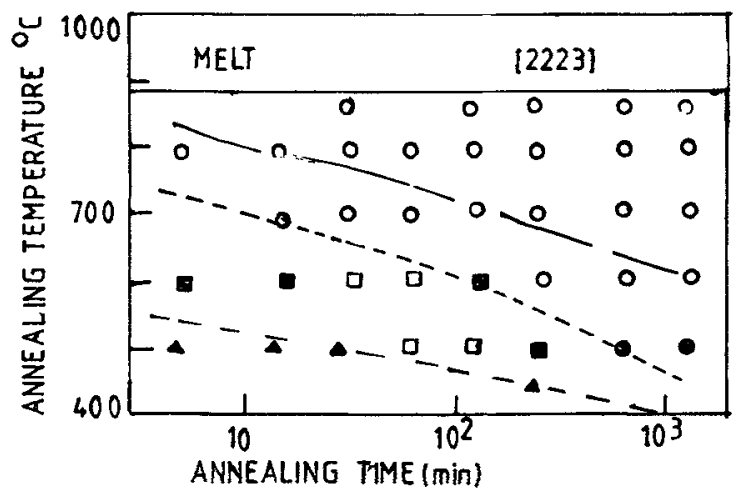

Figure 12. $T-T-T$ diagram for $\mathrm{Bi}_{2} \mathrm{Sr}_{2} \mathrm{Ca}_{2} \mathrm{Cu}_{3} \mathrm{O}_{y}$ glass. $\triangle$ : glass $+\mathrm{Cu}_{2} \mathrm{O}+(\mathrm{CaO}),: 80 \mathrm{~K}$ phase $+\mathrm{CaO}+\mathrm{Cu}_{2} \mathrm{O},: 80 \mathrm{~K}$ phase $+\mathrm{CaO}+\mathrm{CuO},: 80 \mathrm{~K}$ phase $+\mathrm{CaO}+\mathrm{Cu}_{2} \mathrm{O}+\mathrm{CuO},: 80 \mathrm{~K}$ phase $+\mathrm{CaO}, \mathrm{O}: 80 \mathrm{~K}$ phase (Komatsu et al 1989 ). 
oxygen partial pressure. The amount of $\mathrm{Cu}(\mathrm{I})$ ions in these glasses depends on the cooling rate and thus their crystallization behaviour is affected by condition of glass making. The glass preparation conditions have an effect (Zheng et al 1991a, b) on the ratio $\mathrm{Cu}(\mathrm{I}) / \mathrm{Cu}$ (total) in the glass which in turn affects the glass structure and its crystallization mechanism. The glasses melted at lower temperature have lower values of this ratio and yield larger crystallites. The value of this ratio also changes with increase/decrease of melting time. So it is always advisable to melt all glass compositions of a particular base glass at fixed temperature, if possible, and quench them for making superconducting samples.

The initial crystallization phase precipitating out of a glass depends on the composition and also on the ratio $\eta=\mathrm{Cu}(\mathrm{I}) / \mathrm{Cu}$ (total). The initial crystallization phase from the $\mathrm{Bi}_{4} \mathrm{Sr}_{3} \mathrm{Ca}_{3} \mathrm{Cu}_{4} \mathrm{O}_{y}$ glass is 2201 phase. The glasses with low $\eta$ value produces large 2201 crystals and vice versa. It might be possible to control crystallization by controlling the atmosphere and the ratio $\eta$ since crystal growth needs oxygen and the size of the crystal depends on ratio $\eta$. Continuous glass fibre drawing is possible (Zheng et al 1991a, b) by using higher values of $\eta$. In this connection we would like to mention that all these glasses with $\mathrm{Cu}$ ions behave like transition metal oxide glasses and are semiconducting in nature as mentioned earlier (Som et al 1992). The semiconductivity arises due to the presence of mixed valence states of $\mathrm{Cu}$. Elaborate investigations of the semiconducting properties of the $\mathrm{Bi}$-based $\mathrm{Li}$ and $\mathrm{Pb}$ doped glasses have been carried out in our laboratory (Mollah et al 1993, 1994).

A single phase $110 \mathrm{~K}$ superconductor has been prepared (Shi et al 1988, 1989) by crystallization of $\mathrm{Bi}_{2} \mathrm{Sr}_{2} \mathrm{Ca}_{3} \mathrm{Cu}_{4} \mathrm{O}_{y}$ and $\mathrm{Bi}_{2} \mathrm{Sr}_{2} \mathrm{Ca}_{4} \mathrm{Cu}_{5} \mathrm{O}_{y}$ glasses by annealing at $870^{\circ} \mathrm{C}$ in air. The starting composition as well as annealing temperature are important for obtaining a $110 \mathrm{~K}$ phase. The $80 \mathrm{~K}$ and the $\mathrm{Ca}_{2} \mathrm{CuO}_{3}$ phases first coprecipitate from the glass. The $110 \mathrm{~K}$ phase nucleates and grows at the interface between these two phases which is controlled by interface diffusion of calcium and copper.

Like undoped $\mathrm{Bi}-\mathrm{Sr}-\mathrm{Ca}-\mathrm{Cu}-\mathrm{O}$ system $\mathrm{Pb}$ doped system has also been elaborately studied (Mollah et al 1993, 1994). Thorough investigations of $T-T-T$ diagrams for the $\mathrm{Ba}_{1 \cdot 8} \mathrm{~Pb}_{0.2} \mathrm{Sr}_{2} \mathrm{Ca}_{2} \mathrm{Cu}_{3} \mathrm{O}_{y}$ and $\mathrm{Ba}_{1 \cdot 6} \mathrm{~Pb}_{0.4} \mathrm{Sr}_{2} \mathrm{Ca}_{2} \mathrm{Cu}_{3} \mathrm{O}_{y}$ glasses were conducted by Tatsumisago et al (1990). The $\mathrm{Ca}_{2} \mathrm{PbO}_{4}$ phase is formed in the $\mathrm{Bi}-\mathrm{Pb}-\mathrm{Sr}-\mathrm{Ca}-\mathrm{Cu}-\mathrm{O}$ glass on short term annealing at $855^{\circ} \mathrm{C}$. However, on long term annealing the $\mathrm{Ca}_{2} \mathrm{PbO}_{4}$ phase disappears and $110 \mathrm{~K}$ phase is formed. It therefore appears that $\mathrm{Ca}_{2} \mathrm{PbO}_{4}$ plays an important role on the formation of the high $T_{\mathrm{c}}$ phase in the $\mathrm{Pb}$ doped glassy precursors for high $T_{\mathrm{c}}$ superconductors.

\section{Dependence of $T_{\mathrm{c}}$ and $J_{\mathrm{c}}$ on the processing conditions}

It has already been mentioned that if the glasses of our present interest are annealed at a higher temperature (above $T_{\mathrm{g}}$ ) they become crystalline and ultimately superconducting depending on various factors like glass melting temperature, quenching rate, atmosphere, and also on the cooling rate. Therefore, it is not very easy to satisfy all the conditions at a time for achieving high $T_{\mathrm{c}}$ and high $J_{\mathrm{c}}$ values for a particular glass concentration. Furthermore, superconducting properties as well as $J_{\mathrm{c}}$ values also depend on the glass compositions. That is, if all the processing conditions are similarly maintained for two different compositions of the $\mathrm{Bi}-\mathrm{Sr}-\mathrm{Ca}-\mathrm{Cu}-\mathrm{O}$ glasses, for example, the $T_{\mathrm{c}}$ and $J_{\mathrm{c}}$ values might not be the same. It is further mentioned that 
the glass melting temperature, superconducting transition temperature etc also depend on the additives like $\mathrm{Pb}, \mathrm{K}, \mathrm{Li}$, iodine etc. Some typical results on the dependence of $T_{\mathrm{c}}$ and $J_{\mathrm{c}}$ on some of the above mentioned factors are discussed below in brief.

Figure 13 shows the variation of $T_{\mathrm{c} 0}$ (zero resistance temperature) of $\mathrm{Bi}_{x} \mathrm{SrCaCu}_{2} \mathrm{O}_{y}$ glasses annealed at $840^{\circ} \mathrm{C}$ for $45 \mathrm{~h}$ in air and then furnace cooled. There are some optimum values of $x$ for which $T_{\mathrm{c} 0}$ is maximum. However, the glasses $\mathrm{Bi}_{1 \cdot 2} \mathrm{SrCa}_{z} \mathrm{Cu}_{2} \mathrm{O}_{y}$ annealed under the same condition show variation of $T_{\mathrm{c} 0}$ with $z$ (calcium content) as shown in figure 14 . Here $T_{\mathrm{c} 0}$ does not depend very much on the Ca content in the glass. The variation of electrical resistivity of a typical $\mathrm{Bi}_{1 \cdot 2} \mathrm{SrCaCu}_{2} \mathrm{O}_{y}$ glass sample is shown in figure 15 where the sample is annealed at various temperatures. $T_{\mathrm{c}}$ increases with increase of annealing temperature, but for very high temperature annealing $T_{\mathrm{c}}$ decreases appreciably.

The effect of annealing time on $T_{\mathrm{c}}$ and $J_{\mathrm{c}}$ for the $\mathrm{Bi}_{2} \mathrm{Sr}_{2} \mathrm{CaCu}_{2} \mathrm{O}_{y}$ (or 2212) glass sample annealed at $820^{\circ} \mathrm{C}$ in air is shown in figures 16 and 17 . Weak links at the grain boundaries are responsible for low values of $J_{c}$ in the glass-ceramic superconductors.

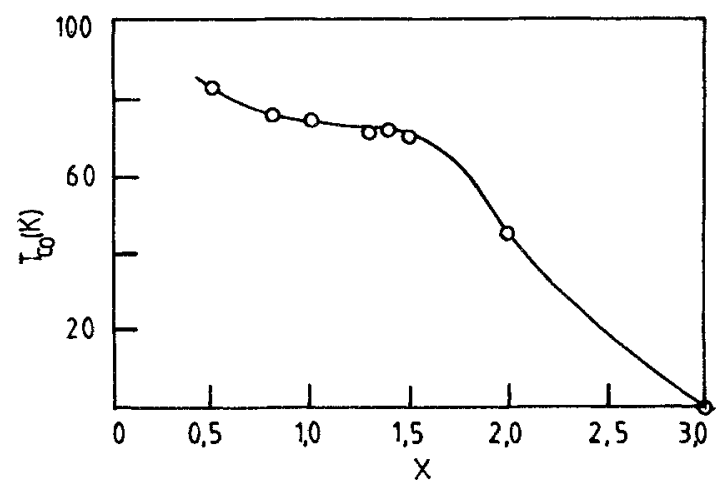

Figure 13. Superconducting transition temperatures, $T_{\mathrm{c}}(R=0)$, of $\mathrm{Bi}_{x} \mathrm{SrCaCu}_{2} \mathrm{O}_{y}$ glasses annealed at $820^{\circ} \mathrm{C}$ for $40 \mathrm{~h}$ in air and furnace cooled (Komatsu et al 1989).

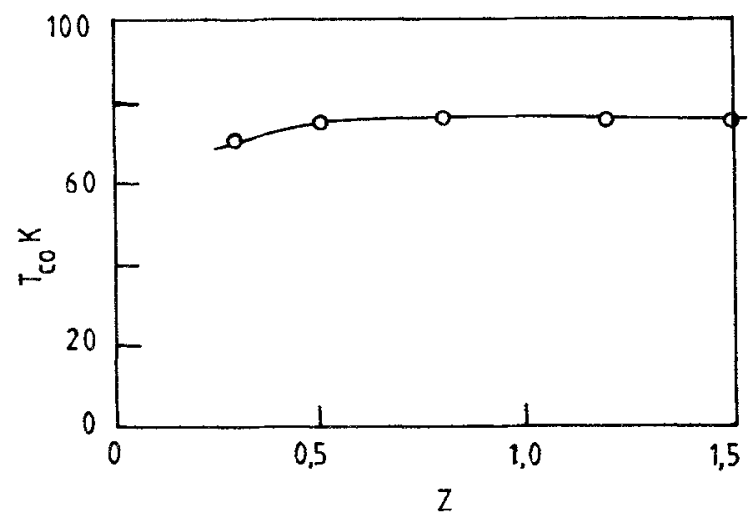

Figure 14. Superconducting transition temperatures, $T_{\mathrm{c}}(R=0)$, of $\mathrm{Bi}_{1 \cdot 2} \mathrm{SrCa}_{z} \mathrm{Cu}_{2} \mathrm{O}_{y}$ glasses annealed at $820^{\circ} \mathrm{C}$ for $40 \mathrm{~h}$ in air furnace cooled (Komatsu et al 1989). 


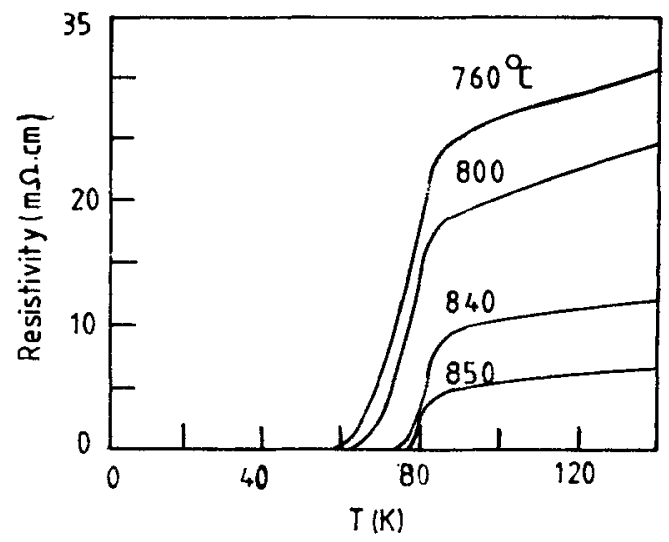

Figure 15. Variation of resistivity of a typical $\mathrm{Bi}_{12} \mathrm{SrCaCu}_{2} \mathrm{O}_{y}$ glass with annealing temperature ( $T_{\mathrm{c} 0}$, zero resistance).

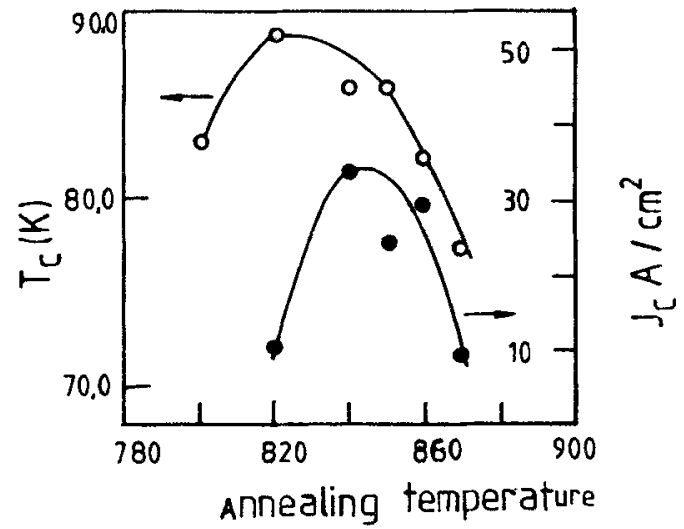

Figure 16. Effect of annealing temperature on critical current density $\left(J_{\mathrm{c}}\right)$ and $T_{\mathrm{c} 0}$.

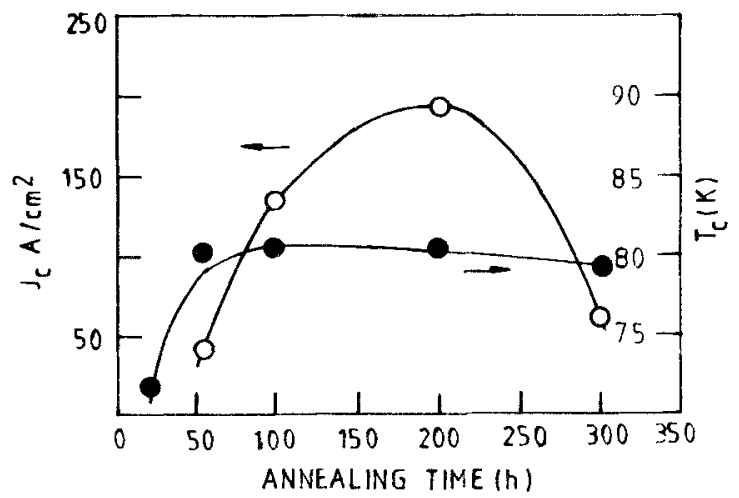

Figure 17. Values of critical temperature $T_{c}$ and critical current density $J_{i}(77 \mathrm{~K}$, zero magnetic field) of $\mathrm{Bi}_{2} \mathrm{Sr}_{2} \mathrm{CaCu}_{2} \mathrm{O}_{y}$ glass samples annealed at $820^{\circ} \mathrm{C}$ in air for various times and furnace cooled (Komatsu et al 1990). 
Recently, efforts are being made to reduce the density of weak links at the grain boundaries. Air, oxygen or vacuum annealed samples have different $T_{\mathrm{c}}$ values (Gan and $\mathrm{Li}$ 1991). Annealing in $\mathrm{O}_{2}$ greatly enhances $T_{c}$ of $\mathrm{Bi}_{4} \mathrm{Sr}_{3} \mathrm{Ca}_{3} \mathrm{Cu}_{4} \mathrm{O}_{x}$ type glasses to a value of $110 \mathrm{~K}$. The vacuum annealed sample has small $T_{c}(75 \mathrm{~K}$ or so) with very low $T_{\mathrm{c} 0}$.

The rate at which a sample is cooled after annealing at higher temperature largely affects the superconducting transition temperature. The $\mathrm{Bi}_{1.5} \mathrm{SrCaCu}_{2} \mathrm{O}_{y}$ glass, for example, annealed at $840^{\circ} \mathrm{C}$ for $90 \mathrm{~h}$ in air followed by fast cooling showed (Bansal and Guire 1989; Guire et al 1990) semiconducting behaviour in the normal state. On the other hand, similar sample annealed similarly and cooled slowly showed metallic in the normal state. The glass sample annealed at $840^{\circ} \mathrm{C}$ for $200 \mathrm{~h}$ is superconducting at $77 \mathrm{~K}$. However, it is interesting to note that the $\mathrm{BiSrCaCu}_{2} \mathrm{O}$ glass sample annealed at $850^{\circ} \mathrm{C}$ for $24 \mathrm{~h}$ in oxygen and cooled rapidly (Komatsu et al 1988) showed a sharp superconducting transition and higher $T_{\mathrm{c}}$, whereas the furnace cooled sample showed a broad transition with a tail and low $T_{\mathrm{c}}$ value. The effect of cooling conditions on the superconducting properties of $\mathrm{Bi}_{1 \cdot 2} \mathrm{SrCaCu}_{2} \mathrm{O}_{y}$ and $\mathrm{Bi}_{2} \mathrm{Sr}_{2} \mathrm{CaCu}_{2} \mathrm{O}_{y}$ glassceramics have also been investigated. Two glass samples of $\mathrm{Bi}_{1 \cdot 2} \mathrm{SrCaCu}_{2} \mathrm{O}_{y}$ compositions were annealed at $880^{\circ} \mathrm{C}$ for $20 \mathrm{~h}$ in air and one sample was rapidly quenched in air and the other was furnace cooled. The temperature dependence of electrical resistivities of these samples is shown in figure 18. The quenched sample has a high normal state resistivity with a sharp drop at $90 \mathrm{~K}$ followed by a long tail which persists to very low temperature. On the other hand, the furnace cooled sample showed a much smaller value of normal state resistivity. It also exhibited a drop in resistivity at $105 \mathrm{~K}$ indicating the formation of high $T_{\mathrm{c}}$ phase followed by a sharp drop at $85 \mathrm{~K}$ with $T_{c}$ at $68 \mathrm{~K}$ (zero resistance value). The effect of cooling condition on the value of $T_{\mathrm{c}}$ of the glass-ceramics obtained by annealing a glass of $\mathrm{Bi}_{2} \mathrm{Sr}_{2} \mathrm{CaCu}_{2} \mathrm{O}_{y}$ composition at $820^{\circ} \mathrm{C}$ for $48 \mathrm{~h}$ in air differs from that of similar glass like $\mathrm{Bi}_{1 \cdot 2} \mathrm{Sr}_{2} \mathrm{CaCu}_{2} \mathrm{O}_{y}$. The normal state resistivity of the furnace cooled sample was smaller than that of the air cooled sample. But the former showed a $T_{\mathrm{c}}(R=0$ value) of $85 \mathrm{~K}$ compared with $88 \mathrm{~K}$ for the latter. The reason for this difference in behaviour is not clear. The influence of various cooling rates on $T_{c}$ of $\mathrm{BiSrCaCu}_{2} \mathrm{O}_{y}$, $\mathrm{Bi}_{2} \mathrm{Sr}_{2} \mathrm{Ca}_{2} \mathrm{Cu}_{3} \mathrm{O}_{y}, \mathrm{Bi}_{3} \mathrm{Sr}_{3} \mathrm{Ca}_{3} \mathrm{Cu}_{4} \mathrm{O}_{y}$ and $\mathrm{Bi}_{3} \mathrm{Sr}_{3} \mathrm{Ca}_{4} \mathrm{Cu}_{5} \mathrm{O}_{y}$ glasses annealed for 24

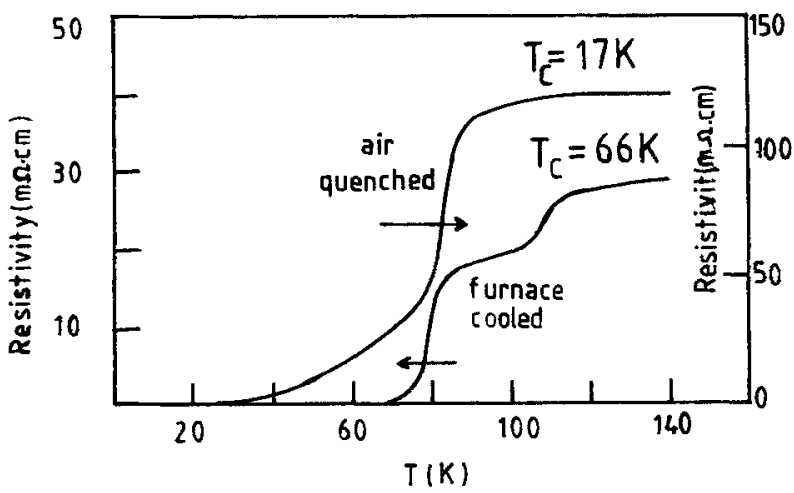

Figure 18. Temperature dependence of electrical resistivity of $\mathrm{Bi}_{1 \cdot 2} \mathrm{SrCaCu}_{2} \mathrm{O}_{y}$ glass samples annealed for $20 \mathrm{~h}$ in air. 
or $48 \mathrm{~h}$ at $870-888^{\circ} \mathrm{C}$ in air, $\mathrm{O}_{2}$, or vacuum has also been studied (Som et al 1992; Chatterjee et al 1994). The $T_{\mathrm{c}}$ (onset) increased with decrease in cooling rate.

The $\mathrm{Pb}$ and $\mathrm{Li}$ doped $\mathrm{Bi}-\mathrm{Sr}-\mathrm{Ca}-\mathrm{Cu}-\mathrm{O}$ systems have also been elaborately investigated in recent years because of the fact that addition of $\mathrm{Pb}$ or $\mathrm{Li}$ reduces the glass transition temperature as well as increases the superconducting transition temperature as mentioned earlier. Temperature dependence of resistivity of $\mathrm{Pb}$ doped $\mathrm{Bi}_{4-n} \mathrm{~Pb}_{n} \mathrm{Sr}_{3} \mathrm{Ca}_{3} \mathrm{Cu}_{4} \mathrm{O}_{x}$ (with $n=0 \cdot 1,0 \cdot 5$ and $0 \cdot 1$ ) is shown in figure 19. These glass ceramics are obtained by annealing the glasses at $840^{\circ} \mathrm{C}$ for $24 \mathrm{~h}$ in air. All the samples show $T_{\mathrm{c}}$ between 110 and $115 \mathrm{~K}$ which is about 10 to $15^{\circ}$ higher than the corresponding undoped systems. Similar curves with $\mathrm{Li}$ doped $\mathrm{Bi}_{4} \mathrm{Sr}_{3} \mathrm{Ca}_{3-2} \mathrm{Li}_{z} \mathrm{Cu}_{4} \mathrm{O}_{x}$ systems have also been studied (Mollah et al 1993). Interesting informations are obtained from the thermoelectric power (TEP) measurements of both the glass and the glass ceramics. For the glasses thermopower is negative (electronic carrier) but for the superconducting glass-ceramics the thermopower is found to be positive (hole carriers). In figure 20 we have shown the temperature dependence of thermoelectric power of the $\mathrm{Pb}$-doped $\mathrm{Bi}_{4} \mathrm{Sr}_{3} \mathrm{Ca}_{3} \mathrm{Cu}_{4} \mathrm{O}_{x}$ glass-ceramics. Choice of correct starting composition to prepare the $110 \mathrm{~K}$ superconducting phase in the bismuth system is also very important. $\mathrm{Bi}_{1 \cdot 84} \mathrm{~Pb}_{0 \cdot 34} \mathrm{Sr}_{2} \mathrm{Ca}_{2} \mathrm{Cu}_{3} \mathrm{O}_{y}$ composition results in the formation of the $75 \mathrm{~K}$ phase whereas $110 \mathrm{~K}$ phase is mainly produced in the $\mathrm{Bi}_{1.84} \mathrm{~Pb}_{0.3} \mathrm{Sr}_{2} \mathrm{Ca}_{2} \mathrm{Cu}_{4} \mathrm{O}_{y}$. Recently, we have been successful in preparing 110 to $115 \mathrm{~K}$ phase in the Po doped

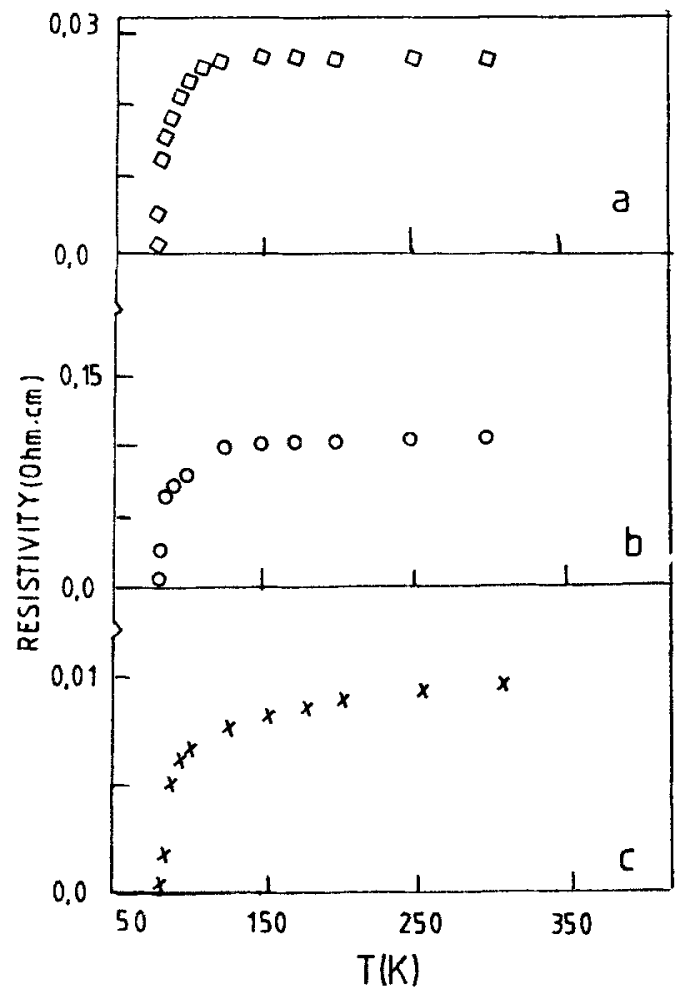

Figure 19. Temperature dependence of electrical resistivity of $\mathrm{Bi}_{4-n} \mathrm{~Pb}_{n} \mathrm{Sr}_{3} \mathrm{Ca}_{3} \mathrm{Cu}_{4} \mathrm{O}_{x}$ glass ceramics $(n=0.1,0.5$ and 1.0$)$. (a) $n=0 \cdot 1$, (b) $n=0.5$ and (c) $n=1 \cdot 0$. 


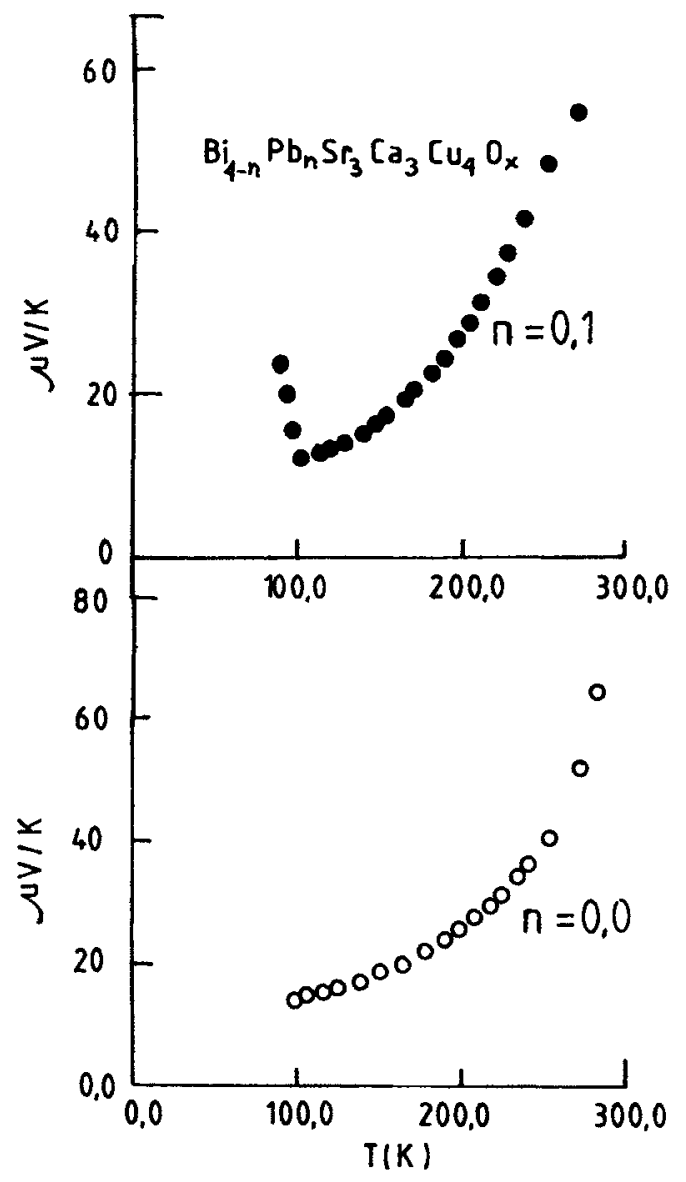

Figure 20. Temperature dependence of thermopowers of $\mathrm{Bi}_{4-n} \mathrm{~Pb}_{n} \mathrm{Sr}_{3} \mathrm{Ca}_{3} \mathrm{Cu}_{4} \mathrm{O}_{x}$ glassceramics $(n=0 \cdot 0,0 \cdot 1)$.

$\mathrm{Bi}_{4} \mathrm{Sr}_{3} \mathrm{Ca}_{3} \mathrm{Cu}_{4} \mathrm{O}_{x}$ glass-ceramics (Bose 1994; Chatterjee et al 1994; Mollah et al 1994). It has also been shown by Baker et al (1989) that superconducting 2212 phase is obtained from the $\mathrm{Bi}_{4} \mathrm{Sr}_{3} \mathrm{Ca}_{3} \mathrm{Cu}_{4} \mathrm{O}_{x}$ glassy precursor. The influence of $\mathrm{Pb}$ content on the superconductivity of the nominal compositions $\mathrm{BiPb}_{x} \mathrm{Sr}_{2} \mathrm{Ca}_{2} \mathrm{Cu}_{3} \mathrm{O}_{y}$, $\mathrm{Bi}_{1-x} \mathrm{~Pb}_{x} \mathrm{Sr}_{2} \mathrm{Ca}_{2} \mathrm{Cu}_{3}, \mathrm{Bi}_{1-x} \mathrm{~Pb}_{x} \mathrm{Sr}_{2} \mathrm{Ca}_{2} \mathrm{Cu}_{3 \cdot 6} \mathrm{O}_{y}$ etc systems have also been elaborately investigated. The optimum value of $x$ for higher $T_{\mathrm{c}}$ was found to be 0.3 to 0.35. At higher $\mathrm{PbO}$ concentration $\mathrm{Ca}_{2} \mathrm{PbO}_{4}$ formed which caused the formation of low $T_{c}$ phase. $\mathrm{PbO}$ can be added until the $\mathrm{Ca}_{2} \mathrm{PbO}_{4}$ is formed in the glass-ceramic phase. Pure 2223 phase has been formed with $\mathrm{Pb}$ addition (Hatano et al 1988; Koyama et al 1988; Luo et al 1990). However, the effect of $\mathrm{Pb}$ substitution is not well understood. $\mathrm{Pb}$ is considered to be partially substituted (Takano et al 1988) into the bismuth oxide planes of the crystal structure of the $110 \mathrm{~K}$ phase. The effect of this substitution is to stabilize the lattice and to facilitate the formation of the pure 2223 phase. Addition of $\mathrm{PbO}$ or $\mathrm{LiO}$ lowers the melting point as well as increases the viscosity of the glass probably by acting as a fluxing agent. The $\mathrm{Pb}$ atoms are easily incorporated 
into the structure probably because $\mathrm{Bi}$ in the $3^{+}$oxidation state and $\mathrm{Pb}$ in the $2^{+}$ state have the same outer electronic shell configuration of $6 s^{2} 6 p^{\circ}$ (Bansal 1992). On the other hand, substitution of the bigger $\mathrm{Pb}^{2+}$ cation (ionic radius $=1.20 \mathrm{~A}$ ) for $\mathrm{Bi}^{3+}$ (ionic radius $=0.96 \mathrm{~A}$ ) probably results in the distortion of the crystal lattice.

Values of critical temperature $T_{\mathrm{c}}$ and critical current density $J_{\mathrm{c}}$ (at $77 \mathrm{~K}$ and zero magnetic field) of a typical $\mathrm{Bi}_{0 \cdot 8} \mathrm{~Pb}_{0 \cdot 2} \mathrm{SrCaCu}_{x} \mathrm{O}_{y}(x=1.5,1.8$ and 1.2) glass-ceramics annealed at $840^{\circ} \mathrm{C}$ in air is shown in figure 21 . Excess amount of $\mathrm{CaO}$ or $\mathrm{CuO}$ always reduces $J_{\mathrm{c}}$ values in the glass-ceramics. The $\mathrm{Pb}$-doped high $T_{\mathrm{c}}$ phase has been observed with high resolution transmission electron microscopy and it was found that $\mathrm{Pb}$ atoms were located in the $\mathrm{Bi}-\mathrm{O}$ layers with an atomic ratio of $\mathrm{Pb} / \mathrm{Bi}$ being $0 \cdot 1$. It is also observed that for low $\mathrm{Pb} / \mathrm{Bi}$ ratio, $\mathrm{Pb}$ atoms incorporated into the structure of both the low $T_{\mathrm{c}}$ and high $T_{\mathrm{c}}$ phases, whereas for high $\mathrm{Pb}$ content $(x>0 \cdot 25)$ the $\mathrm{Pb}$ rich phase appeared. From all such considerations it appears that a value of $x \sim 0 \cdot 2$ would be the optimum substitution of $\mathrm{Pb}$ for $\mathrm{Bi}$ for the formation of the high $T_{\mathrm{c}}$ phase in the $\mathrm{Bi}_{1-x} \mathrm{~Pb}_{x} \mathrm{SrCaCu}_{1.5} \mathrm{O}_{y}$ system. This might be closely related to the maximum $\mathrm{Pb}$ content incorporating in the high $T_{\mathrm{c}}$ phase. This is in agreement with the results of many other researchers. The optimum starting glass composition appears to be $\mathrm{Bi}_{1 \cdot 6} \mathrm{~Pb}_{0 \cdot 4} \mathrm{Sr}_{2} \mathrm{Ca}_{2} \mathrm{Cu}_{3} \mathrm{O}_{y}$. When annealed at $840-945^{\circ} \mathrm{C}$ in air for a long time, a large volume fraction of the $110 \mathrm{~K}$ phase is formed in this glass which shows a $T_{\mathrm{co}}$ at $107 \mathrm{~K}$ along with high $J_{c}$ value. There are definitely other possible glass compositions for preparing superconductors with high $T_{\mathrm{c}}$ and high $J_{\mathrm{c}}$ values.

\section{Superconducting wires, tapes, films from glass phase}

We have already discussed in our previous review (Chaudhuri and Som 1992) the development of superconducting wires or tapes from the glassy phases. Glass precursor approach for the preparation of high $T_{\mathrm{c}}$ superconducting fibres is very interesting (Zheng et al 1989, 1991a, b; Onishi et al 1989, 1990, 1991; Komatsu et al 1990; Miller et al 1990; Chaudhuri et al 1989; Bose 1994). So far this technique has been

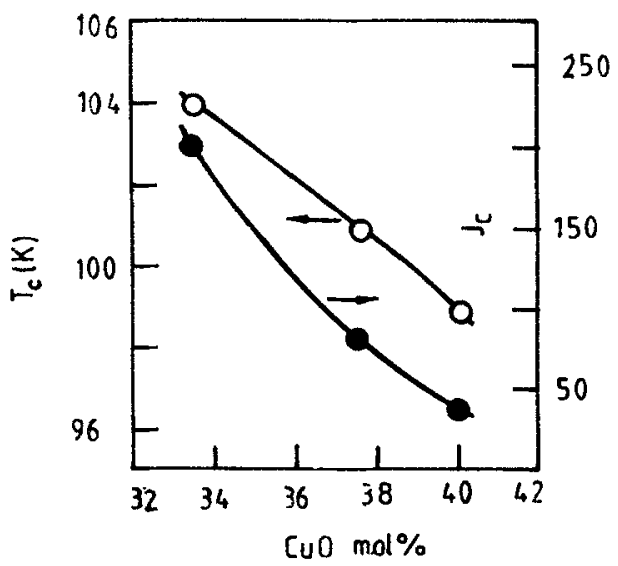

Figure 21. Variations of $J_{c}$ and $T_{c}$ of a typical $\mathrm{Bi}_{0 \cdot 8} \mathrm{~Pb}_{0 \cdot 2} \mathrm{SrCaCu}_{x} \mathrm{O}_{y}$ glass with $\mathrm{CuO}$ content (Komatsu et al 1991). 
used for making fine rods, tapes and thick films of the $\mathrm{Bi}-\mathrm{Sr}-\mathrm{Ca}-\mathrm{Cu}-\mathrm{O}$ or $\mathrm{Pb}-\mathrm{Sr}-$ $\mathrm{Ca}-\mathrm{Cu}-\mathrm{O}$ glassy phases. Continuous glass fibres with diameter $\sim 110 \mu \mathrm{m}$ have been successfully drawn (Zheng et al 1991) with [4334] glass. The superconducting $T_{\mathrm{c}}$ value after heat treatment of about $12 \mathrm{~h}$ is about $85 \mathrm{~K}$. Figure 22 shows some hand drawn fibres from the glass melt. The $J_{\mathrm{c}}$ values for such superconducting wires are relatively small ( 100 to $200 \mathrm{~A} / \mathrm{cm}^{2}$ ). Glass fibres of several diameters have also been drawn from the $\mathrm{Pb}$ doped $\mathrm{Bi}-\mathrm{Sr}-\mathrm{Ca}-\mathrm{Cu}-\mathrm{O}$ glassy phase (Komatsu et al 1990) with $T_{\mathrm{c}}$ as high as $109 \mathrm{~K}$ and $J_{\mathrm{c}}=1480 \mathrm{~A} / \mathrm{cm}^{2}$ (Komatsu et al 1990). Attempts have also been made for fabrication of long fibres from melts of 2212 phase and 1112 phase using a gas jet fibreization technique. Glass fibres of short lengths have also been prepared (Zheng et al 1989) by spinning a melt of 4334 glass. Another technique of making glass wire by depositing glass melt on Pt wires has also been made (Bhargava et al 1991). Interesting development has been made in recent years to make fine filaments or powder by spraying the liquid melts. Another technique involves the glass coating on metal or ceramic surfaces and subsequent annealing to make high $T_{\mathrm{c}}$ superconductors.

\section{Summary and conclusion}

We have reviewed some of the properties of the glass-ceramic superconductors as prepared and studied by different researchers. Most of the studies on the GC phase have been concentrated on the $\mathrm{Bi}-\mathrm{Sr}-\mathrm{Ca}-\mathrm{Cu}-\mathrm{O}$ based systems either undoped or doped with $\mathrm{Pb}, \mathrm{Li}$ etc. $\mathrm{Y}-\mathrm{Ba}-\mathrm{Cu}-\mathrm{O}$ and $\mathrm{Tl}-\mathrm{Ba}-\mathrm{Ca}-\mathrm{Cu}-\mathrm{O}$ systems have not been well studied in their respective GC phases as they are difficult to prepare in the respective glassy phase. However, homogeneous glass is formed when $\mathrm{Y}-\mathrm{Ba}-\mathrm{Cu}-\mathrm{O}$ is mixed with appropriate amount of $\mathrm{B}_{2} \mathrm{O}_{3}$ and $\mathrm{PbO}$. Crystalline $\mathrm{Y}-\mathrm{Ba}-\mathrm{Cu}-\mathrm{O}$ can be nucleated in this glass by proper annealing treatment. Such studies are being made in recent years. Because of the presence of transition metal ions $\left(\mathrm{Cu}^{1+}\right.$ and $\left.\mathrm{Cu}^{2+}\right)$ all the glassy phases showing semiconducting behaviour are almost similar in their behaviour with those of usual TMO glasses. Superconductivity in the glassy phase has not been observed in any of the glasses down to $8 \mathrm{~K}$ or so. However, very recently

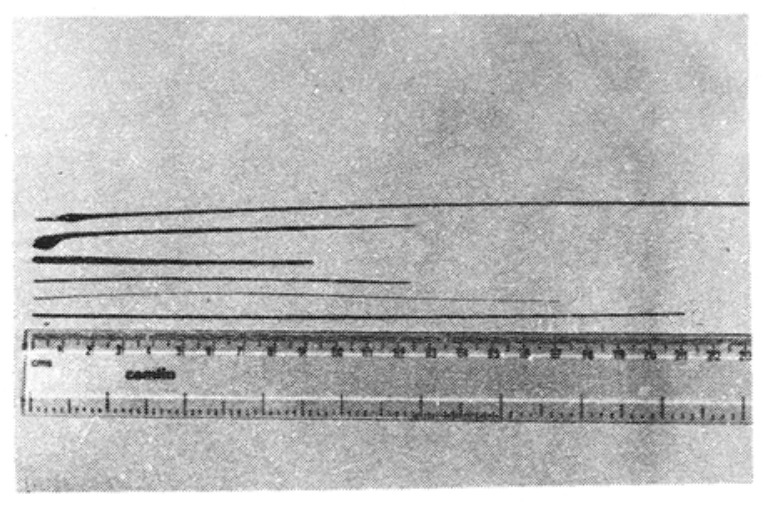

Figure 22. Glass-ceramic superconducting wires from $\mathrm{Bi}_{3.5} \mathrm{~Pb}_{0.5} \mathrm{Sr}_{3} \mathrm{Ca}_{3} \mathrm{Cu}_{4} \mathrm{O}_{x}$ glassy precursors. 
we have observed some increase in the conductivity of the $\mathrm{Pb}$-doped $\mathrm{Bi}_{4-n} \mathrm{~Pb}_{n} \mathrm{Sr}_{3}$ $\mathrm{Ca}_{3} \mathrm{Cu}_{4} \mathrm{O}_{x}$ glasses in the low temperature (below $150 \mathrm{~K}$ ) region but they do not show superconductivity down to $10 \mathrm{~K}$. Moreover, the ac conductivity $\left(\sigma_{\mathrm{ac}}(\omega)\right)$ of the TMO glasses show the general behaviour like $\sigma_{\mathrm{ac}}(\omega) \propto \omega^{\mathrm{s}}$ (where the exponent is $\leqslant 1$ ). But most of the glasses becoming high $T_{\mathrm{c}}$ superconductors show slightly greater value of $s$ than unity in the low temperature region. Furthermore, these glasses also show quite large glass transition temperature, and Debye type dielectric relaxation behaviour. In the $\mathrm{Bi}$-based glasses one also observes the presence of $\mathrm{BiO}_{3}$ and $\mathrm{BiO}_{6}$ structural units. $\mathrm{Bi}_{2} \mathrm{O}_{3}$ acts as the glass former and plays an important role increasing the thermal stability factor $\left(T_{\mathrm{x}}-T_{\mathrm{g}}\right)$ with increase of $\mathrm{Bi}_{2} \mathrm{O}_{3}$ in the glass which is essential for drawing glass fibres from the melts. Very interesting behaviour was shown by the $\mathrm{Ba}-\mathrm{K}$ ( $\mathrm{Li}$ or $\mathrm{Na}$ )- $\mathrm{Bi}-\mathrm{O}$ based glasses. Most of these glasses showed non-linear variations of $\mathrm{dc}$ and ac conductivities and even semiconductor-metal-semiconductor like transition was exhibited between 300 and $340 \mathrm{~K}$ (depending on concentrations). These glasses also showed superconductivity in their ceramic phases (when annealed in oxygen atmosphere). The strong electron-phonon interaction can be attributed to explain the above mentioned non-linear behaviour. However, proper understanding of the behaviour of these and similar other glasses becoming high $T_{\mathbf{c}}$ superconductors in their GC phases has not been possible. The nature of carriers in these glasses are negative as observed from the thermoelectric power measurements but with the increase of crystallinity (by annealing) the nature of carrier changes from negative to positive in the superconducting GC phase. More elaborate microstructural and spectroscopic studies of such glasses might be interesting to elucidate the causes as to why these glasses unlike many TMO glasses become superconductors in their GC phases.

\section{Acknowledgement}

The author is grateful to Miss Gargi Banerjee (JRF, DAE), S Chatterjee (JRF, UGC), D K Modak (SRF, CSIR) and S Mollah (Post Doc., CSIR) for their various help and cooperation.

\section{References}

Avrami M 1939 J. Chem. Phys. 71103

Baker R C, Hung W H and Steinfink H 1989 Appl. Phys. Lett. 54371

Bansal N P 1990 J. Appl. Phys. 681143

Bansal N P and Guire De 1989 NASA Cr 185139

Bednorz J G and Muller K A 1986 Z. Phys. B64 189

Bera A K, Banerjee G, Ghosh A K, Modak D K and Chaudhuri B K 1994 Phase Trans. (in press)

Bhargava A, Varshneya A K and Snyder R L 1991 Mat. Letts. 11313

Bose K 1994 Preparation and characterization of some high $T_{c}$ superconducting composites, Ph.D. Thesis, Jadavpur University, Calcutta

Chaudhuri B K and Som K K 1992 Indian J. Phys. A66 37

Chaudhuri B K, Som K K and Sengupta S P 1989 J. Mater. Sci. 8520

Chatterjee S. Banerjee S and Chaudhuri B K 1994 Phys. Rev. B (communicated)

Gan F and Li G 1991 J. Non-Cryst. Solids 13067

Guire de M R, Bansal N P and Kim C J $1990 \mathrm{~J}$. Am. Ceram. Soc. 731165

Hatano T, Aota K, Ikeda S, Nakamura K and Ogawa K 1988 J. Appl. Phys. 27 L2055 
Hirashima H, Watanabe $\mathrm{Y}$ and Yoshida T $1987 \mathrm{~J}$. Non-Cryst. Solids 95 \& 96825

Komatsu T, Kamai K, Matsusita K, Tánaka M, Iwai Y, Kawakami A, Kaneko Y and Yamashita T 1987 Jap. J. Appl. Phys. Lett. 26 L1272, L1148

Komatsu T, Imai K, Goto R, Matsusita K and Yamashita T 1988 Jap. J. Appl. Phys. 27 L533

Komatsu T, Ohki T, Matsusita K and Yamashita T 1989 J. Ceram. Soc. Jap. 97251

Komatsu T, Hirose C, Ohki T and Matsusita K 1990 J. Am. Ceram. Soc. 73-3569

Koo H S, Xu R and Mackenzie J D 1989 J. Mater. Res. 4911

Koyama S, Endo U and Kawai T 1888 Jap. J. Appl. Phys. 27 L1861

LeBeau S E, Righi J, Ostenson J E, Sanders S C and Finnemore D K 1989 Appl. Phys. Lett. 55292

Luo J S, Faudot F, Chevalier J P, Portier R and Michel D 1990 J. Solid State Chem. 8994

Maeda M, Tanaka Y, Fukutomi M and Asano T 1988 Jap. J. Appl. Phys. 27 L209

Michel C, Hervieu M, Borel M M, Grandin A, Deslandes F, Provost J and Raveau B 1987 Z. Phys. B68 421

Michel C, Hervieu M, Borel M M, Grandin A, Deskandes F, Provost J and Raveau B 1987 Z. Phys. B68 431

Miller T A, Sanders S C, Ostenson J E, Finnemore D K, LeBeau S E and Righi J 1990 Appl. Phys. Letts. 56584

Mollah S 1993 Preparation and characterization of some transition metal oxide glasses becoming high $T_{\mathrm{c}}$ superconductors in their glass-ceramic phases, $\mathrm{Ph} . \mathrm{D}$. Thesis, Jadavpur University, Calcutta

Mollah S, Som K K, Bose K and Chaudhuri B K 1993 J. Appl. Phys. 73931

Mollah S, Bera A K, Chakraborty S and Chaudhuri B K 1994 Phys. Rev. B49 1243

Mollah S, Chatterjee S, Chakraborty S and Chaudhuri B K 1994 Philos. Mag. (in press)

Mott N F and Davis E A 1979 in Electronic processes in non-crystalline materials (Oxford: Clarendon) 2nd Ed.

Nakamura S and Ichinose N 1987 J. Non-Cryst. Solids 95 \& 96849

Nassau K, Miller A E. Gyorgy E M and Siegrist T 1989 J. Mater. Res. 41330

Onishi M, Kohgo T, Chigusa Y. Watanabe K, Kyoto M and Watanabe M 1990 Jap. J. Appl. Phys. 29 L64

Onishi M, Kyoto M and Watanabe M 1991 Jap. J. Appl. Phys. 30 L988

Onishi M, Khgo T, Chigusa Y, Kyoto M and Watanabe M 1989 Jap. J. Appl. Phys. 28 L2204

Sadhukhan M, Bera A K and Chaudhuri B K $1994 \mathrm{~J}$. Non-Cryst. Solids (communicated)

Sakuri Y and Yamaki J 1985 J. Electrochem. Soc. 132512

Shi D, Blank M, Patel M, Kinks D G, Mitchell A W, Vandervoot K and Claus H 1988 Physica C156822

Shi D, Jang M, Vandervoorz K and Claus H 1989 Phys. Rev. B39 9091

Som K K 1991 Studies of some semiconducting oxide glasses and some high $T_{\mathrm{c}}$ superconducting oxide compounds, Ph.D. Thesis, Jadavpur University, Calcutta

Som K K, Mollah S, Bose K and Chaudhuri B K 1992 Phys. Rev. B45 1655

Takano M, Takada J, Oda K, Kitaguchi H, Miura Y, Ikeda Y, Tomil Y and Mazaki H 1988 Jap. J. Appl. Phys. 27 L1081

Tatsumisago M, Angell C A, Tsuboi S, Akamatsu Y, Tohge N and Minami T 1989a Appl. Phys. Lett. 54 2268

Tatsumisago M, Angell C A, Tsuboi A, Akamatsu Y, Tohge N and Minami T 1989b Appl. Phys. Lett. 55 6000

Tatsumisago M, Tsubo S, Tohge N and Minami T 1990 Appl. Phys. Lett. 57195

Tohge N, Tsuboi S, Tatsumisago M and Minami T 1989 Jap. J. Appl. Phys. 28 L1742

Zheng $H$ and Mackenzie J D 1991 Phys. Rev. B43 3048

Zheng H, Xu R and Mackenzie J D 1989 J. Mater. Res. 4911

Zheng H, Colby M W and Mackenzie J D 1991a J. Non-Cryst. Solids 1271679

Zheng H, Hu Y and Mackenzie J D 1991b Appl. Phys. Lett. 591679 